\title{
Is urinary neutrophil gelatinase-associated lipocalin able to predict acute kidney injury episodes in very low birth weight infants in clinical settings?
}

\author{
Elvira Parravicini ${ }^{1}$, Chiara Locatelli², John M. Lorenz' ${ }^{1}$, Sheri L. Nemerofsky ${ }^{3}$ and David A. Bateman ${ }^{1}$
}

BACKGROUND: We evaluated the potential utility of elevated urinary neutrophil gelatinase-associated lipocalin (UNGAL) concentration as a screening test for early identification of acute kidney injury (AKI) in very low birth weight (VLBW) newborns.

METHODS: Urine for UNGAL analysis was collected prospectively daily until $32 \mathrm{wk}$ postmenstrual age in $91 \mathrm{VLBW}$ newborns, yielding 2,899 specimens. UNGAL values > $50 \mathrm{ng} / \mathrm{ml}$ were considered elevated. AKI was defined as two or more consecutive elevations in $\mathrm{s}[\mathrm{Cr}]$ above the $95^{\text {th }}$ percentile adjusted for gestational age and chronological age within a $48 \mathrm{~h}$ period. We compared UNGAL values taken during the $5 \mathrm{~d}$ prior to AKI onset (pre-AKI) to values taken during non-AKI days.

RESULTS: Overall, 15 episodes of AKI were identified in 13 infants. UNGAL was available in 44 pre-AKI days and 969 nonAKI days. UNGAL > $50 \mathrm{ng} / \mathrm{ml}$ occurred more often in pre-AKI days than in non-AKI days (risk ratio $3.48(1.89,6.40)$ ). Positive and negative likelihood ratios were $1.92(1.52,2.41)$ and 0.52 $(0.34,0.78)$, respectively.

CONCLUSION: Although UNGAL elevation > $50 \mathrm{ng} / \mathrm{ml}$ discriminates between pre-AKI and non-AKI days, high false positive and false negative rates limit utility as a screening test in VLBW newborns.

V ery low birth weight (VLBW) infants are at high risk for acute kidney injury (AKI) (1) which reduces their survival (2). In clinical practice, serum creatinine concentration $(\mathrm{s}[\mathrm{Cr}])$, as a reflection of glomerular filtration rate, and urine output are used as indicators of renal function. However, oliguria is an insensitive and nonspecific marker for AKI because it may reflect poor renal perfusion rather than injury and because neonates with AKI may not exhibit oliguria (3). In this population, $s[\mathrm{Cr}]$ normally changes after birth as a function of maternal s[Cr], gestational age, and postnatal age (4). Thus, a single $s[\mathrm{Cr}]$ is rarely diagnostic of AKI. Rather, deviation $s[\mathrm{Cr}]$ from the normal pattern of postnatal change is indicative of abnormal renal function (5). A change in $s[\mathrm{Cr}]$ is delayed in relation to the onset of AKI, limiting its usefulness in the early diagnosis of AKI. Identification of a biomarker which is more easily interpreted than $s[\mathrm{Cr}]$ and anticipates the onset of AKI earlier in the course of renal impairment would be useful for diagnosis of AKI in VLBW infants.

Urinary neutrophil gelatinase-associated lipocalin (UNGAL) derives predominantly from the thick limb of Henle and the collecting ducts $(6,7)$ and is found in high concentration in the urine of children and adults with AKI, anticipating the rise of $s[\mathrm{Cr}](8-10)$. A few studies have suggested an association between an increased UNGAL concentration and AKI in VLBW infants. However, these studies were based on UNGAL on random urine collection in the first week of life $(11,12)$ or with very limited number of samples (13) and, more importantly, without regard to an established reference range.

Prior studies have established reference ranges for both UNGAL and $s[\mathrm{Cr}]$ in VLBW infants without risk factors for $\operatorname{AKI}(5,14,15)$. In this study, we used data from a cohort of VLBW infants from whom daily urine samples had been prospectively collected for UNGAL analysis and whose clinical progress and laboratory values were prospectively documented (15). The study objectives were to establish the timing of elevation of UNGAL in relation to the onset of AKI and to assess the characteristics of UNGAL as a potential screening test for AKI.

\section{RESULTS}

Ninety-one VLBW infants were recruited for this study within the first week of life (61 at Columbia University Medical Center (CUMC), New York, NY and 30 at Children's Hospital at Montefiore (CHAM), Albert Einstein College of Medicine, New York, NY). Selected characteristics of study infants are shown in Table 1.

A total of 2,899 urine samples (median: 29 daily samples/ infant) were collected and assayed for UNGAL. Sixteen episodes of AKI in 14 patients were identified. However, as UNGAL values were not available during AKI for one patient (parental consent was not yet obtained) 15 episodes of AKI

\footnotetext{
The first two authors contributed equally to this work.

'Department of Pediatrics, College of Physicians and Surgeons, Columbia University, New York, New York; ${ }^{2}$ Department of Pediatrics, University of Bologna, Bologna, Italy;

${ }^{3}$ Department of Pediatrics, Albert Einstein College of Medicine/Montefiore Medical Center, Bronx, New York. Correspondence: Elvira Parravicini, (ep127@cumc.columbia.edu)

Received 15 February 2016; accepted 6 May 2016; advance online publication 10 August 2016. doi:10.1038/pr.2016.138
} 


\section{Articles | Parraviciniet al.}

Table 1. Clinical characteristics of study infants

\begin{tabular}{|c|c|c|c|}
\hline & AKI & No AKI & $P$-value ${ }^{a}$ \\
\hline Number of babies & 13 & 78 & \\
\hline Number of episodes & 15 & --- & \\
\hline $\begin{array}{l}\text { Gestational age } \\
(\text { week })^{b}\end{array}$ & $25 \pm 1$ & $28 \pm 2$ & $<0.001$ \\
\hline Birth weight $(g)^{b}$ & $789 \pm 148$ & $1,083 \pm 268$ & $<0.001$ \\
\hline $\begin{array}{l}\text { Day of life of } \\
\text { AKl episode }^{c}\end{array}$ & $16(9.25,21.75)$ & - & - \\
\hline \multirow{2}{*}{$\begin{array}{l}\text { Length of hospital } \\
\text { stay }^{c}\end{array}$} & $94.5(41.5,129.5)$ & $56.5(30,83.8)$ & 0.20 \\
\hline & $\%$ & $\%$ & OR $(95 \% \mathrm{Cl})$ \\
\hline Male & 53.8 & 60.3 & $0.77(0.24,2.51)$ \\
\hline Hispanic & 65.1 & 48.71 & $1.68(0.51,5.61)$ \\
\hline Prenatal care & 100 & 100 & 1.0 \\
\hline Multiple gestation & 11.1 & 28.8 & $0.31(0.04,2.69)$ \\
\hline Antenatal steroids & 88.9 & 90.4 & $0.85(0.01,8.27)$ \\
\hline Vaginal delivery & 23.1 & 28.6 & $0.75(0.19,2.99)$ \\
\hline Apgar $<5,1 \mathrm{~min}$ & 30.8 & 20.5 & $1.72(0.47,6.32)$ \\
\hline Apgar $<5,5 \mathrm{~min}$ & 7.7 & 3.8 & $2.08(0.20,21.7)$ \\
\hline $\begin{array}{l}\text { Mechanical } \\
\text { ventilation }\end{array}$ & 88.9 & 44.2 & $10.1(1.18,86.6)$ \\
\hline $\mathrm{PDA}^{\mathrm{d}}$ & 76.9 & 46.2 & $3.89(0.99,15.2)$ \\
\hline Ligation of PDA $^{d}$ & 38.5 & 16.7 & $3.12(0.88,11.1)$ \\
\hline $\begin{array}{l}\text { Late-onset sepsis } \\
(>72 \mathrm{~h})\end{array}$ & 30.8 & 15.4 & $2.44(0.65,9.23)$ \\
\hline
\end{tabular}

OR, odds ratio; $\mathrm{Cl}$, confidence interval; PDA, patent ductus arteriosus; AKI, acute kidney injury.

a $P$-value derived from independent samples $t$-test or Wilcoxon rank-sum test, as appropriate. ${ }^{\mathrm{b}}$ Mean $\pm \mathrm{SD}$. ${ }^{\mathrm{c}}$ Median (interquartile range). ${ }^{\mathrm{d}}$ Patent ductus arteriosus.

were included in the analysis. Concurrent patterns of mean UNGAL concentration and mean change in $\mathrm{s}[\mathrm{Cr}]$ from day 0 baseline are displayed in Figure $\mathbf{1 a}$ (raw version) and Figure $\mathbf{1 b}$ (smoothed version).

UNGAL was available in 44 pre-AKI days and 969 non-AKI days. UNGAL > $50 \mathrm{ng} / \mathrm{ml}$ occurred more often in pre-AKI days than in non-AKI days (risk ratio $3.48(1.89,6.40)$ ). Positive and negative likelihood ratios were $1.92(1.52,2.41)$ and $0.52(0.34$, $0.78)$, respectively.

The proportion of UNGAL values $>50 \mathrm{ng} / \mathrm{ml}$ during specified intervals of the AKI s [Cr] pattern noted in Figure 1 is as follows: non-AKI days $34.4 \%$; pre-AKI (days -5 to 0 ) $65.9 \%$; onset (days 1-2) 91.4\%; and continuation to resolution (days 3-14) $79.8 \%$. The computed risk ratio $(3.48(1.89,6.40))$ and odds ratio (OR $3.69(1.95,6.98)$ ) for the cross-tabulation of pooled UNGAL > $50 \mathrm{ng} / \mathrm{ml}$ vs. pre-AKI are nearly identical and do not differ significantly from the adjusted OR yielded by the generalized estimating equation (OR 3.13, 95\% confidence interval (CI) $1.02,9.61$ ), suggesting that adjustments for gestational age (GA), chronologic age, gender, and within-infant correlations do little to modify the association between UNGAL and AKI. Parameter estimates for the ability of UNGAL $>50 \mathrm{ng} / \mathrm{ml}$ to discriminate between pre-AKI and non-AKI status as defined
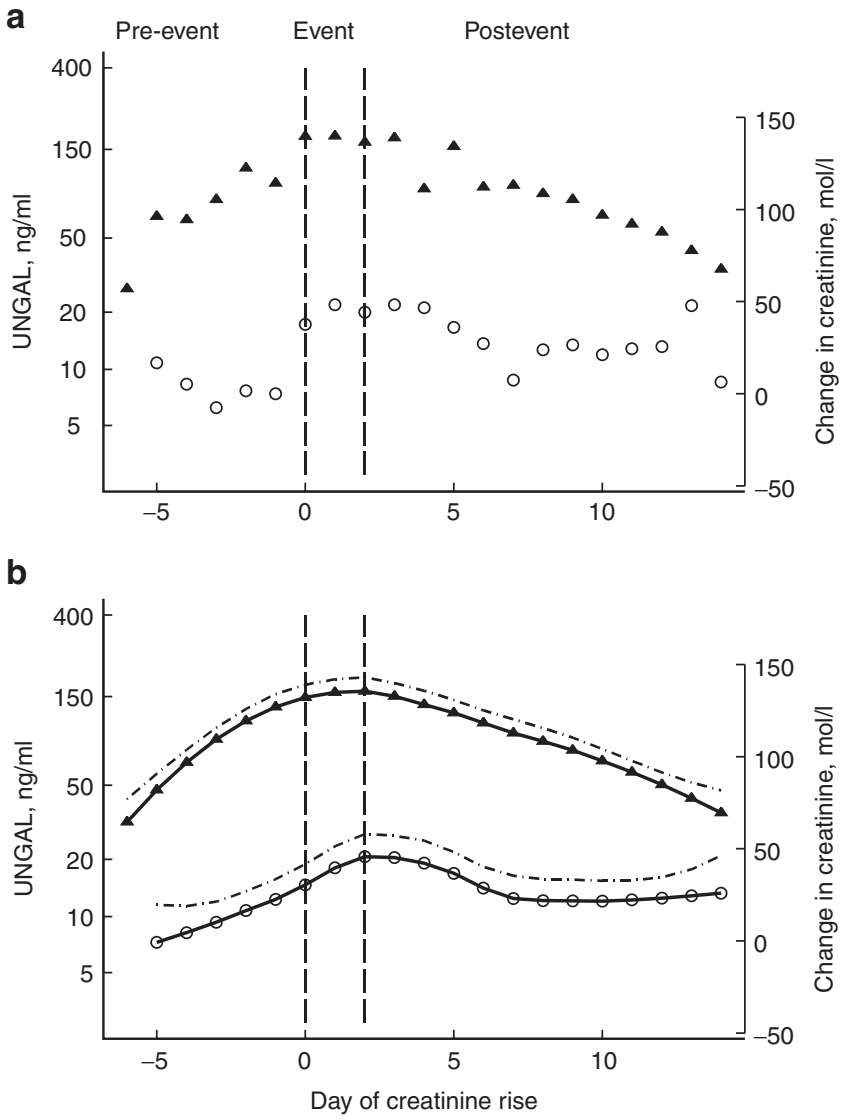

Figure 1. Pooled mean daily urinary neutrophil gelatinase-associated lipocalin (UNGAL) (solid triangles) and serum creatinine concentration $(\mathrm{s}[\mathrm{Cr}]$ )(open circles) values plotted before (pre-event, day- 5 to 0 ), during (day 1,2) and after (day 3-14) acute kidney injury (AKI) episodes. (a) Raw values. (b) Smoothed mean (solid lines) and upper $95^{\text {th }}$ confidence limit (dashed lines) computed using lowess, a locally weighted scatterplot smoother.

by each of the two different criteria used for AKI are shown in Table 2.

In this sample of infants numerous elevations of UNGAL above the reference range were noted outside AKI episodes, often in association with morbid events other than AKI. Figure 2 displays overlying UNGAL and s[Cr] plots for a $25 \mathrm{wk}$ GA infant whose hospital course was complicated initially by severe respiratory distress syndrome and hypotension requiring pressor infusion, a large patent ductus arteriosus requiring surgical closure (age $25 \mathrm{~d}$ ), necrotizing enterocolitis (age $43 \mathrm{~d}$ ), and Staphylococcus Aureus sepsis (age $66 \mathrm{~d}$ ). Although variable, UNGAL values exceeded the $50 \mathrm{ng} / \mathrm{ml}$ cut-off for long portions of the hospitalization when $s[\mathrm{Cr}]$ remained within the normal range.

\section{DISCUSSION}

Although not the first to investigate the role of UNGAL as a biomarker for AKI in VLBW infants, this study is the largest, as well as the first to examine concurrent patterns of UNGAL and $s[\mathrm{Cr}]$ change in a cohort of infants in whom data collection was prospective and not conditioned on the presence or 
Table 2. UNGAL screening test parameter estimates derived for AKI for each of the two different criteria used for AKI

\begin{tabular}{|c|c|c|c|c|c|c|}
\hline & \multicolumn{3}{|c|}{$\begin{array}{c}\text { AKI criteria via } \\
\text { percentile curves }\end{array}$} & \multicolumn{3}{|c|}{$\begin{array}{l}\text { AKI defined as rise in } \\
s[\mathrm{Cr}] \geq 0.3 \mathrm{mg} / \mathrm{dl}(3,27)\end{array}$} \\
\hline & \multirow[b]{2}{*}{$\begin{array}{l}\text { Estimated } \\
\text { value }\end{array}$} & \multicolumn{2}{|c|}{$95 \% \mathrm{Cl}$} & \multirow[b]{2}{*}{$\begin{array}{l}\text { Estimated } \\
\text { value }\end{array}$} & \multicolumn{2}{|c|}{$95 \% \mathrm{Cl}$} \\
\hline & & $\begin{array}{l}\text { Lower } \\
\text { limit }\end{array}$ & $\begin{array}{l}\text { Upper } \\
\text { limit }\end{array}$ & & $\begin{array}{l}\text { Lower } \\
\text { limit }\end{array}$ & $\begin{array}{l}\text { Upper } \\
\text { limit }\end{array}$ \\
\hline Prevalence & 0.04 & 0.03 & 0.06 & 0.03 & 0.02 & 0.04 \\
\hline Sensitivity & 0.66 & 0.50 & 0.79 & 0.61 & 0.42 & 0.78 \\
\hline Specificity & 0.66 & 0.63 & 0.69 & 0.63 & 0.60 & 0.66 \\
\hline $\mathrm{PPV}^{\mathrm{a}}$ & 0.08 & 0.06 & 0.11 & 0.05 & 0.03 & 0.08 \\
\hline$N P V^{b}$ & 0.98 & 0.96 & 0.99 & 0.98 & 0.97 & 0.99 \\
\hline $\mathrm{LR}+{ }^{c}$ & 1.92 & 1.52 & 2.41 & 1.65 & 1.23 & 2.21 \\
\hline LR-d $^{d}$ & 0.52 & 0.34 & 0.78 & 0.62 & 0.39 & 0.96 \\
\hline Risk ratio & 3.48 & 1.89 & 6.40 & 2.60 & 1.28 & 5.30 \\
\hline Odds ratio & 3.69 & 1.95 & 6.98 & 2.68 & 1.29 & 5.59 \\
\hline $\begin{array}{l}\text { Adjusted } \\
\text { odds ratio }\end{array}$ & 3.13 & 1.02 & 9.61 & & & \\
\hline $\mathrm{AOC}^{\mathrm{e}}$ & 0.70 & 0.64 & 0.77 & 0.62 & 0.52 & 0.72 \\
\hline
\end{tabular}

UNGAL, urinary neutrophil gelatinase-associated lipocalin; AKl, acute kidney injury; $\mathrm{s}[\mathrm{Cr}]$, serum creatinine concentration.

a. PPV, positive predictive value. ${ }^{\text {b. } N P V}$, negative predictive value. ${ }^{\complement} \mathrm{LR}+$, positive likelihood ratio. ${ }^{d}$ LR-, negative likelihood ratio; ${ }^{~} A O C$ : area under the curve in a receiver-operator curve.

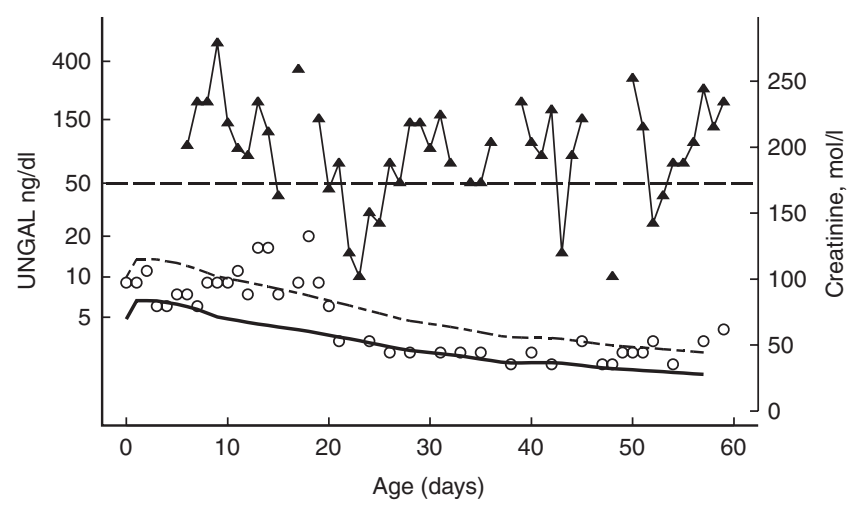

Figure 2. Daily UNGAL (solid triangles) and $s(\mathrm{Cr})$ (open circles) values in a 25 wk GA infant with severe RDS and hypotension requiring pressor infusion (day 0-10), large PDA requiring surgical closure (day 25), NEC (day 43), and Staphylococcus Aureus sepsis (day 66). GA-specific mean (solid) and upper $95^{\text {th }}$ percentile (broken) $s(\mathrm{Cr}$ ) lines are depicted (5). The horizontal dashed line at UNGAL $50 \mathrm{ng} / \mathrm{dl}$ shows the $95^{\text {th }}$ percentile cut-off value (15). UNGAL, urinary neutrophil gelatinase-associated lipocalin; $\mathrm{s}[\mathrm{Cr}]$, serum creatinine concentration; PDA, patent ductus arteriosus; RDS, respiratory distress syndrome; GA, gestational age; NEC, necrotizing enterocolitis. Reprinted from refs. 5 and 15.

likelihood of AKI. Daily urine collections, yielding almost 3,000 NGAL assays, enabled the specific temporal association of UNGAL production and AKI to be investigated. UNGAL elevation above the reference range was noted in about $2 / 3$ of the samples collected within 5 days before the sustained $s[\mathrm{Cr}]$ elevation. While these results may be suggestive of a potential role of UNGAL as early diagnostic marker of AKI, the fact that about $1 / 3$ of urine samples taken during non-AKI days were also elevated clearly diminishes this potential.
This is not unexpected. The performance of biomarkers in a clinical context in which the patient is a low risk of the outcome of interest is significantly poorer than in clinical context in which the risk of the outcome is high. Troponin I as a biomarker of myocardial ischemia is one example (16). Basu et al. (17) have proposed using "renal angina criteria" in settings of subtle AKI to identify patients at high risk and thus improve the performance of AKI biomarkers. However, given that most morbidities which VLBW infants experience are risk factors for AKI and that this and previous studies have demonstrated that these morbidities are often associated with elevations of NGAL in the absence of AKI (18-20), it is unlikely that the identification of clinical contexts would improve the performance of UNGAL as a biomarker of AKI in this population.

Our results were computed using a UNGAL cutoff value of $50 \mathrm{ng} / \mathrm{ml}$, chosen because it provided a reasonable balance between sensitivity and specificity on the ROC, and because it corresponds to the $95^{\text {th }}$ percentile of an established reference range (15). Alternative cut-off values $(20 \mathrm{ng} / \mathrm{ml}$ and $120 \mathrm{ng} / \mathrm{ml})$ altered, but did not improve the ability, of UNGAL to identify AKI.

Askenazi et al. (11) studied the ability of UNGAL and other urinary biomarkers to predict AKI and mortality in VLBW infants. The authors reported significantly higher levels of NGAL in the urine of nine VLBW infants with AKI when compared with that of another group of 21 VLBW infants who did not have AKI. Tabel et al. (12) examined UNGAL values on day 1 and $7 \mathrm{in}$ a population of 50 premature infants (GA: $28-34 \mathrm{wk}$ ) and showed a significant increase in UNGAL concentration in six patients with AKI compared with that of other critically ill infants with normal renal function. Both studies involved a small number of urine samples collected over the first few days of life and had limited ability to explore screening test characteristics of UNGAL. In a pilot study, Sarafidis et al. (13) compared the UNGAL values of 11 VLBW infants affected by AKI to those of 11 VLBW, matched by GA and postnatal age, without AKI. The urine specimens were obtained $2 \mathrm{~d}$ before and the day on which the criteria for AKI were met in the AKI group. Although it demonstrated higher values of UNGAL at the time of AKI diagnosis, the study failed to show any role of UNGAL in early detection of AKI. The authors concluded that a much larger investigation may clarify the potential use of UNGAL to predict AKI in clinical settings.

An intriguing aspect of our study is that UNGAL was so frequently elevated during periods when renal function as measured by serum creatinine was normal. An association between elevated UNGAL and conditions other than AKI has been noted in adults $(21,22)$. In VLBW infants UNGAL is up regulated in late-onset sepsis, even in presence of normal renal function $(18,19)$. Populations of unselected VLBW infants have high proportions of morbidities including patent ductus arteriosus, sepsis, necrotizing enterocolitis and intraventricular hemorrhage, which may be associated with elevated UNGAL (20). These conditions (and their treatments) may produce kidney injury without impairing renal function via inflammatory mediators, diminished perfusion, or via toxins 


\section{Articles $\mid$ Parraviciniet al.}

and toxic medications that must be excreted. Baseline UNGAL values in studies of unselected VLBW infants are higher than those obtained from a cohort of infants from whom those with severe morbidities and risk factors for kidney injury have been excluded $(15,23)$.

Elevations in UNGAL in the presence of normal renal function may point to non-AKI triggers for NGAL synthesis. In response to bacterial infection the innate immune system produces NGAL to limit bacterial growth by iron sequestration (24). NGAL in urine and serum exists in different forms that can be distinguished by molecular weight. While the dimeric form is secreted by neutrophils, kidney epithelial cells synthesize mostly the monomeric form (25). In animal models filtered serum NGAL is efficiently cleared by the proximal tubule (22), while urinary NGAL is almost entirely derived from the renal tubules themselves. However, in VLBW infants with pathologic conditions including sepsis, the origin of UNGAL is not known. In such settings it is possible that a portion of UNGAL derives from the circulating pool. In mouse models, toll-like receptor expression is essential to NGAL production (24) and UNGAL is excreted in response to infection (26). Thus, filterable bacterial products may reach the kidney tubule to activate these toll-like receptors in the renal tubules. One of the limitations of our study is that we could not assess the precise molecular weight and thus determine the origin of the NGAL found in the urine. It is possible that screening test characteristics of UNGAL for AKI may be enhanced by a test that measures only the monomeric form.

A second, and perhaps more important, limitation of our study relates to the definitions of AKI: one is based on a change in the statistically-derived pattern of $s[\mathrm{Cr}](5)$, the other corresponds to an arbitrary change in absolute value of serum creatinine, as proposed by the Acute Kidney Injury Network (27) and by Jetton et al. (3). A discussion of the limitations of serum creatinine as the gold standard for renal injury is beyond the scope of this report, but must be emphasized that there is emerging evidence that kidney injury might be better identified by a framework that utilizes biomarkers that reflect renal function and damage (28).

In conclusion, UNGAL is neither sensitive nor specific for AKI in VLBW infants, when serum creatinine is used as gold standard. Further prospective studies are required to explore new diagnostic frameworks leading to early identification of kidney injury in clinical settings.

\section{METHODS}

\section{Study Subjects}

This observational study recruited VLBW infants (Birth weight $<1,500 \mathrm{~g}$ ) born at CUMC from March 2007 to March 2008 and at CHAM from November 2007 to March 2008. Exclusion criteria were: infants with major congenital anomalies, abnormal karyotypes, anticipation of early death or transfer to a referring institution, and small for gestational age. Parental consent for study participation was obtained and the study was approved by the Institutional Review Board at each institution.

\section{Fluid and Electrolyte Management of Infants}

The infants were cared for in incubators servo-controlled to an abdominal skin temperature of $36.0-36.5^{\circ} \mathrm{C}$, with a relative humidity of $60 \%$.
Initially, i.v. fluid volume was $80-100 \mathrm{ml} / \mathrm{kg} / \mathrm{d}$ during the first $24 \mathrm{~h}$ of life, increasing progressively to $120 \mathrm{ml} / \mathrm{kg} / \mathrm{d}$ by $48-72 \mathrm{~h}$ age. Serum electrolytes were usually measured 2-3 times daily in the first few days of life and less frequently thereafter. Sodium was usually not added to the i.v. fluids until the third day of life. Small-volume enteral feeds using expressed human milk or formula were initiated as soon as infants achieved cardiorespiratory stability and the volume of i.v. fluid was readjusted to compensate for enteral intake. The feeds were progressively advanced, thereafter, to a volume of $160 \mathrm{ml} / \mathrm{kg} / \mathrm{d}$. The fluid intake and urine output were recorded hourly; weight was measured daily.

\section{UNGAL and Creatinine Analysis}

Bagged spot urine samples were collected on the day of enrolment (usually in the first week of life), and daily until $32 \mathrm{wk}$ postmenstrual age, discharge or death, whichever occurred first. The urine was centrifuged within $24 \mathrm{~h}$ of collection and the supernatant stored at $-80^{\circ} \mathrm{C}$. NGAL concentration was determined by immunoblot as previously described (15). UNGAL analysis occurred after infants had been discharged. All $s[\mathrm{Cr}] \mathrm{s}$ obtained during the normal course of care during the study period were included in the analyses. Then, $s[\mathrm{Cr}]$ was obtained on the same day of the urine collection by $95 \%$ of the time. It was measured using a kinetic modification of the Jaffe method on Beckman Coulter AU 2700 and AU 640 analyzers (Beckman Coulter, Brea, CA). The method of analysis remained unchanged during the study period. Results conformed to standard values generated by isotope dilution mass spectrometry (29). Manufacturer reports no significant interference (within 10\% of initial value) for serum bilirubin levels up to $20 \mathrm{mg} / \mathrm{dl}$ (30).

\section{Case Definition and Data Collection}

AKI was defined as two or more consecutive elevations in $\mathrm{s}[\mathrm{Cr}]$ above the $95^{\text {th }}$ percentile adjusted for GA and chronological age within $48 \mathrm{~h}$ (5). Because this standard is not in common use we alternately defined AKI as a s[Cr] increase from baseline of $\geq 0.3 \mathrm{mg} / \mathrm{dl}(26.5 \mu \mathrm{mol} / \mathrm{l})$ for at least two creatinine values within a $48 \mathrm{~h}$ period $(3,27)$. Day 0 of AKI was defined as the first day of the sustained increase of $\mathrm{s}[\mathrm{Cr}]$. We defined elevated UNGAL as $>50 \mathrm{ng} / \mathrm{ml}$, corresponding to the $95^{\text {th }}$ percentile range obtained in a prior investigation restricted to VLBW newborns with uncomplicated clinical courses (15). This study found that the reference range for UNGAL was stable across a wide range of gestational and chronological ages, justifying the use of a single cutoff value for study infants.

\section{Data Exploration}

To visualize concurrent UNGAL and $s[\mathrm{Cr}]$ changes over time we plotted the daily values for each infant on GA and age-specific templates that showed reference mean and upper $95^{\text {th }}$ percentile ranges $(5,15)$. We used these plots to verify AKI events and to examine how UNGAL varied during non-AKI periods. Specifically we identified four periods: non-AKI days; pre-AKI (days -5 to 0 ); onset (days 1-2); and continuation to resolution (days 3-14). We also examined pooled mean daily values around the AKI event (Figure 1a). UNGAL has a log-normal distribution; therefore, daily geometric means are displayed; mean change in $\mathrm{s}[\mathrm{Cr}]$ from baseline value on day 0 is also displayed. Figure 1 suggests that UNGAL elevations begin about 5 days prior to the onset of creatinine elevations (day-5) and persist for at least 14 days. A smoothed version showing the upper $95 \%$ confidence limit for each curve is shown in Figure $1 \mathrm{~b}$. To determine potential attributes of elevated UNGAL as a screening test for AKI, it is of interest to compare UNGAL values in this "pre-AKI" period ( -5 to 0 days) to those from times that are not part of an AKI event ("non-AKI" periods). Therefore, days 0-14 of an AKI event, as well as any subsequent days of continued, persistent elevations of UNGAL or s[Cr], are excluded from the "non-AKI" periods.

\section{Statistical Analysis}

We compared proportions of UNGAL > $50 \mathrm{ng} / \mathrm{ml}$ during pre-AKI and non-AKI periods in both bivariate and multivariate analyses. In the multivariate model, we used a logistic generalized estimating equation to account for correlations among values taken from the same infant and with gestational age, chronological age and gender as covariates. We estimated standard screening test parameters for the ability of UNGAL $>50 \mathrm{ng} / \mathrm{ml}$ to discriminate between pre-AKI and non-AKI states. 


\section{STATEMENT OF FINANCIAL SUPPORT}

There is no financial support.

Disclosure: There are no conflicts of interest.

\section{REFERENCES}

1. Walker MW, ClarkRH,Spitzer AR. Elevation in plasma creatinineand renalfailure in premature neonates without major anomalies: terminology, occurrence and factors associated with increased risk. J Perinatol 2011;31:199-205.

2. Koralkar R, Ambalavanan N, Levitan EB, McGwin G, Goldstein S, Askenazi D. Acute kidney injury reduces survival in very low birth weight infants. Pediatr Res 2011;69:354-8.

3. Jetton JG, Askenazi DJ. Update on acute kidney injury in the neonate. Curr Opin Pediatr 2012;24:191-6.

4. Gallini F, Maggio L, Romagnoli C, Marrocco G, Tortorolo G. Progression of renal function in preterm neonates with gestational age $\leq 32$ weeks. Pediatr Nephrol 2000;15:119-24.

5. Bateman DA, Thomas W, Parravicini E, Polesana E, Locatelli C, Lorenz JM. Serum creatinine concentration in very-low-birth-weight infants from birth to 34-36 wk postmenstrual age. Pediatr Res 2015;77:696-702.

6. Schmidt-Ott KM, Mori K, Kalandadze A, et al. Neutrophil gelatinaseassociated lipocalin-mediated iron traffic in kidney epithelia. Curr Opin Nephrol Hypertens 2006;15:442-9.

7. Schmidt-Ott KM, Mori K, Li JY, et al. Dual action of neutrophil gelatinaseassociated lipocalin. J Am Soc Nephrol 2007;18:407-13.

8. Mori K, Lee HT, Rapoport D, et al. Endocytic delivery of lipocalin-siderophore-iron complex rescues the kidney from ischemia-reperfusion injury. J Clin Invest 2005;115:610-21.

9. Mishra J, Dent C, Tarabishi R, et al. Neutrophil gelatinase-associated lipocalin (NGAL) as a biomarker for acute renal injury after cardiac surgery. Lancet 2005;365:1231-8.

10. Zappitelli M, Washburn KK, Arikan AA, et al. Urine neutrophil gelatinaseassociated lipocalin is an early marker of acute kidney injury in critically ill children: a prospective cohort study. Crit Care 2007;11:R84.

11. Askenazi DJ, Montesanti A, Hunley H, et al. Urine biomarkers predict acute kidney injury and mortality in very low birth weight infants. J Pediatr 2011;159:907-12.e1.

12. Tabel Y, Elmas A, Ipek S, Karadag A, Elmas O, Ozyalin F. Urinary neutrophil gelatinase-associated lipocalin as an early biomarker for prediction of acute kidney injury in preterm infants. Am J Perinatol [online] 2013. http://dx.doi.org/ 10.1055/s-0033-1343770.

13. Sarafidis K, Tsepkentzi E, Diamanti E, et al. Urine neutrophil gelatinaseassociated lipocalin to predict acute kidney injury in preterm neonates. A pilot study. Pediatr Nephrol 2014;29:305-10.

14. Parravicini E, Lorenz JM, Nemerofsky SL, O’Rourke M, Barasch J, Bateman D. Reference range of urinary neutrophil gelatinase-associated lipocalin in very low-birth-weight infants: preliminary data. Am J Perinatol 2009;26:437-40.

15. Huynh TK, Bateman DA, Parravicini E, et al. Reference values of urinary neutrophil gelatinase-associated lipocalin in very low birth weight infants. Pediatr Res 2009;66:528-32.
16. Stein R, Gupta B, Agarwal S, et al. Prognostic implications of normal $(<0.10 \mathrm{ng} / \mathrm{ml})$ and borderline $(0.10$ to $1.49 \mathrm{ng} / \mathrm{ml})$ troponin elevation levels in critically ill patients without acute coronary syndrome. Am J Cardiol 2008;102:509-12.

17. Basu RK, Chawla LS, Wheeler DS, Goldstein SL. Renal angina: an emerging paradigm to identify children at risk for acute kidney injury. Pediatr Nephrol 2012;27:1067-78.

18. Parravicini E, Nemerofsky SL, Michelson KA, et al. Urinary neutrophil gelatinase-associated lipocalin is a promising biomarker for late onset culture-positive sepsis in very low birth weight infants. Pediatr Res 2010;67:636-40.

19. Pynn JM, Parravicini E, Saiman L, Bateman DA, Barasch JM, Lorenz JM. Urinary neutrophil gelatinase-associated lipocalin: potential biomarker for late-onset sepsis. Pediatr Res 2015;78:76-81.

20. Tosse V, Pillekamp F, Verde P, et al. Urinary NT-proBNP, NGAL, and $\mathrm{H}$-FABP may predict hemodynamic relevance of patent ductus arteriosus in very low birth weight infants. Neonatol 2012;101:260-6.

21. Tomonaga Y, Szucs T, Ambühl P, Nock S, Risch M, Risch L. Insights on urinary NGAL obtained in a primary care setting. Clin Chim Acta 2012;413:733-9.

22. Singer E, Markó L, Paragas N, et al. Neutrophil gelatinase-associated lipocalin: pathophysiology and clinical applications. Acta Physiol (Oxf) 2013;207:663-72.

23. Askenazi DJ, Koralkar R, Levitan EB, et al. Baseline values of candidate urine acute kidney injury biomarkers vary by gestational age in premature infants. Pediatr Res 2011;70:302-6.

24. Flo TH, Smith KD, Sato S, et al. Lipocalin 2 mediates an innate immune response to bacterial infection by sequestrating iron. Nature 2004;432: 917-21.

25. Cai L, Rubin J, Han W, Venge P, Xu S. The origin of multiple molecular forms in urine of HNL/NGAL. Clin J Am Soc Nephrol 2010;5: 2229-35.

26. Paragas N, Qiu A, Zhang Q, et al. The Ngal reporter mouse detects the response of the kidney to injury in real time. Nat Med 2011;17: 216-22.

27. Mehta RL, Kellum JA, Shah SV, et al.; Acute Kidney Injury Network. Acute Kidney Injury Network: report of an initiative to improve outcomes in acute kidney injury. Crit Care 2007;11:R31.

28. Murray PT, Mehta RL, Shaw A, et al.; ADQI 10 workgroup. Potential use of biomarkers in acute kidney injury: report and summary of recommendations from the $10^{\text {th }}$ Acute Dialysis Quality Initiative consensus conference. Kidney Int 2014;85:513-21.

29. Myers GL, Miller WG, Coresh J, et al.; National Kidney Disease Education Program Laboratory Working Group. Recommendations for improving serum creatinine measurement: a report from the Laboratory Working Group of the National Kidney Disease Education Program. Clin Chem 2006;52:5-18.

30. Creatinine, OSR BAOSR6x78.02 General Chemistry. Beckman Coulter, Brea, CA, 2010. https://www.beckmancoulter.com/wsrportal/ techdocs?docname=/cis/BAOSR6x78A/\%25\%25/EN_CREATININE.pdf. 